\title{
Centimeter per Second
}

National Cancer Institute

\section{Source}

National Cancer Institute. Centimeter per Second. NCI Thesaurus. Code C102406.

A unit of both speed (scalar) and velocity (vector), defined as the distance of one

centimeter travelled per unit time equal to one second. 